\section{Kidney \\ Blood Pressure Research}

Kidney Blood Press Res 2015;40:605-613

DOI: 10.1159/000368536

Publisned onine: November 29, 2015

Accepted: October 22, 2015

\title{
Effects of Renin-Angiotensin System Inhibitors on Renal Expression of Renalase in Sprague-Dawley Rats Fed With High Salt Diet
}

\author{
Yang Wang ${ }^{a, b}$ Bing-Qing Xie ${ }^{a, b}$ Wei-Hua Gao ${ }^{c}$ Ding-Yi Yan ${ }^{a, b}$ Wen-Ling \\ Zheng ${ }^{a, b}$ Yong-Bo Lva,b Yu-Meng Cao ${ }^{a, b} \quad$ Jia-Wen Hua,b Zu-Yi Yuana,b \\ Jian-Jun $\mathrm{Mu}^{\mathrm{a}, \mathrm{b}}$ \\ aDepartment of Cardiology, First Affiliated Hospital of Medical College, Xi'an Jiaotong University, \\ ${ }^{b}$ Key Laboratory of Molecular Cardiology of Shaanxi Province, 'Department of Cardiology, Xi'an NO.1 \\ Hospital, Xi'an, P. R. China
}

\section{Key Words}

Renin-angiotensin system $•$ Renalase $\cdot$ Salt $•$ Proteinuria

\begin{abstract}
Background/Aims: The aim of our study was to investigate the effect of high-salt diet on the renal expression of renalase and the potential role of the local renin-angiotensin system in this process. Methods: Sprague-Dawley (SD) rats were divided into groups according to salt content in diet and drug treatment as follows: normal-salt diet (NS), high-salt diet (HS), highsalt intake with hydralazine $(\mathrm{HS}+\mathrm{H})$, high-salt diet with enalapril $(\mathrm{HS}+\mathrm{E})$, and high-salt diet with valsartan $(\mathrm{HS}+\mathrm{V})$. The dietary intervention and drugs were given for four weeks. Renin activity and angiotensin II type 1 receptor (AT1R) levels were detected by real-time PCR. Renalase mRNA and protein were also measured. Results: After four weeks, systolic blood pressure and proteinuria were significantly increased in the HS group with respect to the NS group. Dietary salt intake caused a dramatic decrease in renalase expression in the rat kidneys. Renal cortex renin and AT1R increased significantly in the HS and HS $+\mathrm{H}$ groups. Urinary protein was positively correlated with renal renin and AT1R levels. However, in the HS+E and HS+V groups, enalapril and valsartan failed to influence renal renalase expression but abolished the increase in proteinuria, renal cortex renin, and AT1R levels with respect to the HS group. Conclusion: This study indicates that high salt intake reduces renal expression, and renal RAS may be not involved in the regulation of renalase in SD rats fed with high-salt diet.
\end{abstract}

Y. Wang, B.-Q. Xie and W.-H. Gao contributed equally to this work and therefore share first authorship

Jian-Jun Mu, PhD

KARGER 125
Department of Cardiology, First Affiliated Hospital of Medical College, Xian Jiaotong University, No.277, Yanta West Road, Xi'an ,710061 (P. R. China) Tel. +86-29-85323804, E-Mail mujjun@163.com 


\section{Kidney Blood Pressure Research}

\section{Introduction}

Renalase, first discovered in 2005, is a flavin-adenine-dinucleotide-dependent amine oxidase that is secreted into the blood by the kidneys and is hypothesized to participate in catecholamine metabolism [1]. Several cells can synthesize and secrete renalase, but renal proximal tubules are the major sites from which renalase originates [2,3]. Previous evidence revealed that recombinant renalase exerts powerful and rapid hypotensive effects on rats; this effect was suggested to be mediated by the degradation of circulating catecholamines, which could decrease cardiac contractility and heart rate $[4,5]$. Whether renalase is an amine oxidase or not is presently debated. Aliverti and Moran et al. [6-8] failed to demonstrate the catalytic activity of renalase, which is contradictory to the investigation reported by Xu et al. [1]. Thus, additional evidence is needed to confirm whether renalase is an amine oxidase. Renalase deficiency has been reportedly associated with chronic kidney disease, heart disease, diabetes, stroke, and hypertension [9-12].

Excess dietary salt is strongly correlated with cardiovascular disease, morbidity, and mortality; it is considered to be a major contributing factor to the pathogenesis of hypertension $[13,14]$. Recent findings have shown that high dietary salt decreases blood and kidney renalase levels in rats subjected to subtotal nephrectomy as well as in Dahl saltsensitive rats [15]. These results were demonstrated by our recent studies, in which we found that high-salt diet causes a significant decrease in serum renalase levels and increase in urinary renalase secretion in Chinese adults $[16,17]$. In addition, we recently showed that polymorphisms of the renalase gene were associated with blood-pressure (BP) responses to dietary salt intake in a family-based study [18]. However, the relationship between salt intake and renalase expression has not been fully established and deserves further investigation.

The renin-angiotensin system (RAS) is the circulating endocrine system that regulates blood-pressure and electrolyte homeostasis. In addition to the classical systemic RAS, local tissue-specific RASs have also been identified in various organs. The renal RAS was identified and believed to be potentially associated with the regulation of renalase. RAS inhibitors were shown to upregulate renal-tissue and circulating renalase levels in rats with adriamycininduced nephropathy and mice with high-fat intake $[19,20]$. Whether local RAS affects renal renalase expression under the high-salt condition is not understood. We hypothesized that the renal RAS may be involved in the regulation of renalase in the kidney.

Therefore, in this study, we preliminarily explored the possible role of renal RAS in the regulation of renalase by examining the renal renalase expression in Sprague-Dawley (SD) rats fed with a high-salt diet and the effects of enalapril and valsartan on renalase expression.

\section{Materials and Methods}

\section{Animals}

Seven-week-old male SD rats from the Animal Center of the Medical School of Xi'an Jiaotong University were housed in individual cages under controlled light $(12 \mathrm{~h} / 12 \mathrm{~h}$ dark/light cycle) and temperature (20$23^{\circ} \mathrm{C}$ ) conditions. All the rats were allowed to consume standard diet and tap water. The study was carried out in strict accordance with the Guide for the Care and Use of Laboratory Animals of the National Institutes of Health.

\section{Experimental design}

The rats were randomly divided into five groups according to the salt content in the diet and drug treatment as follows: normal salt diet (NS, 0.3\% $\mathrm{NaCl}$ ), high-salt diet ( $\mathrm{HS}, 8 \% \mathrm{NaCl}$ ), high-salt diet with $20 \mathrm{mg} / \mathrm{kg} /$ day of hydralazine (HS+H group; Genshare Biological, Shaanxi, China), high-salt diet with 10 $\mathrm{mg} / \mathrm{kg}$ /day of enalapril (HS+E group; Cisen Pharmaceutical Co., Ltd, Shandong, China), and high-salt diet 


\section{Kidney Blood Pressure Research}

with $40 \mathrm{mg} / \mathrm{kg} /$ day of valsartan (HS+V group; Novartis Inc., Basel, Switzerland). Each group comprised six rats. The treatments were administered daily by gavage. Four rats in each treatment group were placed in metabolic cages for $24 \mathrm{~h}$ urine collection before experiment termination. After four weeks, the rats were given $10 \%$ chloral hydrate injection intraperitoKidney Blood Press Res 2015;40:605-613 \begin{tabular}{|l|l|}
\hline DOI: 10.1159/000368536 & (c) 2015 The Author(s). Published by S. Karger AG, Base
\end{tabular} Published online: November 29, 2015 www.karger.com/kbr

neally for anesthesia. Blood samples were collected from the abdominal aorta to isolate the serum and plasma and then stored at $-80{ }^{\circ} \mathrm{C}$ until analysis. The left kidney was also harvested for study. The right kidney was fixed in $10 \%$ formalin for immunohistochemical examination. The experimental protocols were approved by the Institutional Animal Ethics Committee of Xi'an Jiaotong University.

\section{Physiological and biochemical measurements}

The systolic BP (SBP) of the rats was measured through a noninvasive tail-cuff method using the BP2000 blood-pressure-analysis system (Visitech Systems, USA). All rats performed adaptive training adjusted to blood-pressure measurements by tail-cuff plethysmography prior to the final measurements. A cuff was placed around the tail of each rat and inflated to $240 \mathrm{mmHg}$. The pressure at which the first tail pulse was detected was recorded as the SBP. SBP was measured 10 times, and the average value was calculated. Serum $\mathrm{Na} / \mathrm{K}$, serum creatinine, $24 \mathrm{~h}$ urinary protein, and $24 \mathrm{~h}$ urinary $\mathrm{Na} / \mathrm{K}$ were analyzed using a Hitachi 7060 automatic biochemical analyzer (Hitachi, Ltd., Japan). Plasma renalase levels were measured using a commercially available enzyme-linked immunosorbent assay kit (Uscn Life Science, Inc., Wuhan, China).

\section{Immunohistochemistry}

Immunohistochemistry was conducted as previously reported [21]. Briefly, serial $5 \mu \mathrm{m}$ paraffinembedded tissue sections were dewaxed and rehydrated. Endogenous peroxidase activity was inhibited by incubating the sections in $3.0 \%$ hydrogen peroxide. The sections were incubated overnight at $4{ }^{\circ} \mathrm{C}$ with renalase (Abcam, USA 1:100) antibody and an appropriate secondary antibody at room temperature for $30 \mathrm{~min}$. The sections were photographed through an upright fluorescence microscopic imaging system (BX51 Olympus, Japan). To evaluate the immunoperoxidase stain of renalase, 10 non-overlapping fields at 20× magnification were randomly selected from each kidney section. The immunoperoxidase stain was quantified using the Image Pro Plus 6.0 imaging software (Media Cybernetics, USA). Data were reported as the mean optical density in each field area.

\section{Quantitative real-time PCR}

Total RNA from the kidney tissues was isolated using TRIzol reagent (Takara Bio, Japan). The mRNA expression levels were quantified from the total RNA using real-time PCR with SYBR Premix Ex Taq ${ }^{\text {TM }}$ II (Takara Bio, Japan). GAPDH was used as an internal control for the mRNAs. The primers employed in this study are shown in Table 1. The protocol for RT-PCR was based on our previous method [21]. The mRNA expression values are shown in folds of mRNA expression in the tissues of SD rats fed with normal salt diet.

\section{Western blot analysis}

The renal tissues were homogenized and lysed with RIPA lysis buffer (Genshare, Shaanxi, China). The supernatant was collected after centrifugation at $14,000 \mathrm{rpm}$ for $15 \mathrm{~min}$ at $4{ }^{\circ} \mathrm{C}$. The proteins were then quantified by the Bradford assay with a protein assay kit. Portions of protein $(30 \mu \mathrm{g})$ per sample were separated through a $10 \%$ sodium dodecyl sulfate-polyacrylamide gel and transferred to nitrocellulose membranes at $30 \mathrm{~V}$ for $1.5 \mathrm{~h}$. Non-specific binding was blocked with $5 \%$ skim milk for $2 \mathrm{~h}$ at room temperature. Subsequently, the membrane was blocked with $5 \%$ skimmed milk in $0.1 \%$ Tris-buffered saline-Tween (TBST) and then probed with antibodies directed against renalase (1:3000; Abcam, Cambridge, UK) or GAPDH (1:1000, 


\section{Kidney Blood Pressure Research}

Cell Signaling Technology, Beverly, MA, USA) at 4 ${ }^{\circ} \mathrm{C}$ overnight, followed by washing thrice in TBST. The membrane was then incubated with horseradish-peroxidase-conjugated anti-rabbit (1:10,000; Thermo Scientific, USA) IgG for $2 \mathrm{~h}$ at room temperature. All the data were obtained from ChemiDoc XRS+ System (Bio-Rad, Hercules, CA, USA) and band intensities were analyzed using Quality One software.

\section{Statistical Analysis}

The statistical soft-

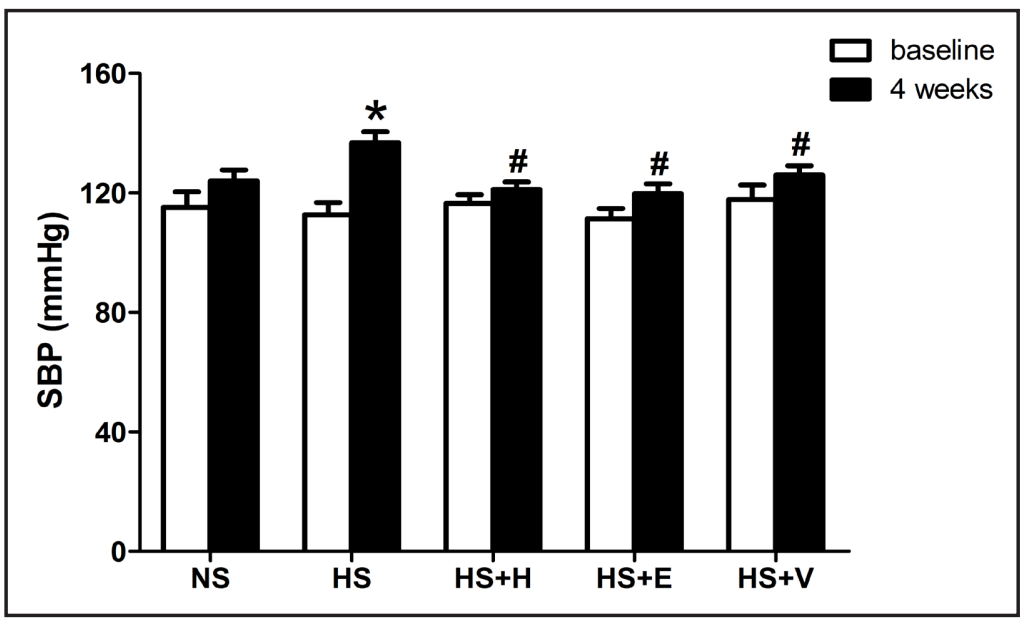

Fig. 1. Systolic blood pressure (SBP) was measured at baseline and 4 weeks in conscious rats by tail-cuff plethysmography, ${ }^{*} P<0.05$ vs. NS group. ${ }^{\#} P<0.05$ vs. HS group.

ware SPSS version 16.0 (Chicago, IL, USA) was used for data analysis. All the data were expressed as mean \pm standard error of the mean. One-way ANOVA and the Kruskal-Wallistestwere usedfor parametricand non-parametric data comparisons, respectively. Correlations were evaluated by the Pearson correlation analysis. A value of $P<0.05$ was considered significant.

\section{Result}

General data of laboratory animals

All rats exhibited normal physiologic activities and were healthy during the dietary intervention. At baseline, no significant differences in SBP were detected among groups. After four weeks of high-salt diet, the SBP of the HS group increased significantly, but was dramatically decreased by enalapril, valsartan, and hydralazine $(P<0.05$, Fig. 1$)$. Moreover, the $24 \mathrm{~h}$ urinary $\mathrm{Na} / \mathrm{K}$ and urinary protein increased sharply in the HS group, but proteinuria was significantly reduced by enalapril and valsartan $(P<0.05$, Table 2$)$.

\section{mRNA expression in the kidney RAS}

To demonstrate the effects of the dietary and drug interventions on renal RAS, we investigated the mRNA expression of renin and AT1R in the renal cortex of the rats in each group. The mRNA expression of renin and AT1R increased significantly in the HS group $(P<0.05)$, remained stable in the $\mathrm{HS}+\mathrm{H}$ group, but was restored by enalapril and valsartan $(P<0.05$; Fig. 2).

In addition, the urinary protein excretions correlated positively with the renal cortex mRNA expression of renin $(\mathrm{r}=0.864, P<0.001)$ and AT1R $(\mathrm{r}=0.51, P=0.022)$ in all groups.

Plasma renalase levels and expression in kidney tissues

Plasma renalase content was dramatically decreased after salt loading when compared with the NS group $(P<0.05$, Table 2$)$ and remained unchanged with respect to the other three groups. Compared with those in the NS group, the renalase protein expression in the HS group decreased markedly $(P<0.05)$. By contrast, renalase protein expression in the HS+H group did not differ from those in the HS group and were not influenced by treatment with either enalapril or valsartan $(P>0.05$, Fig. 3A). As shown in Fig. 3B, renalase mRNA expression also exhibited the same trends among the different groups. 


\section{Kidney \\ Blood Pressure Research}

Table 2. Body weight and biochemical parameters of blood and urine

\begin{tabular}{lccccc}
\hline \multicolumn{1}{c}{ Parameters } & NS & HS & HS+E & HS+V & HS+H \\
\hline serum Creatinine $(\mu \mathrm{mol} / \mathrm{L})$ & $53.35 \pm 3.40$ & $49.30 \pm 2.65$ & $51.60 \pm 4.94$ & $50.13 \pm 3.16$ & $47.68 \pm 2.52$ \\
serum $\mathrm{Na}^{+}(\mathrm{mmol} / \mathrm{L})$ & $139.3 \pm 0.31$ & $139.0 \pm 0.29$ & $139.8 \pm 1.16$ & $140.6 \pm 0.82$ & $138.9 \pm 0.61$ \\
serum $\mathrm{K}^{+}(\mathrm{mmol} / \mathrm{L})$ & $4.69 \pm 0.11$ & $4.67 \pm 0.20$ & $4.61 \pm 0.53$ & $4.59 \pm 0.27$ & $4.80 \pm 0.22$ \\
Plasma renalase $(\mathrm{ng} / \mathrm{ml})$ & $93.9 \pm 2.0$ & $69.6 \pm 3.2^{*}$ & $70.0 \pm 2.2$ & $72.9 \pm 1.0$ & $58.8 \pm 6.4$ \\
24h urinary Na $(\mathrm{mmol})$ & $1.47 \pm 0.47$ & $30.78 \pm 2.45^{*}$ & $25.66 \pm 1.32$ & $36.91 \pm 4.39$ & $24.50 \pm 3.91$ \\
24h urinary K $(\mathrm{mmol})$ & $2.30 \pm 0.63$ & $8.03 \pm 0.72^{*}$ & $5.23 \pm 0.68^{\#}$ & $6.66 \pm 0.72$ & $8.59 \pm 0.86$ \\
24h urinary protein $(\mathrm{mg} / \mathrm{d})$ & $34.1 \pm 9.7$ & $255.6 \pm 37.9^{*}$ & $257.8 \pm 22.2$ & $89.9 \pm 16.5^{\#}$ & $59.0 \pm 8.0^{\#}$ \\
body weight $(\mathrm{mg})$ & $472.3 \pm 10.3$ & $402.0 \pm 11.4^{*}$ & $344.0 \pm 3.7^{\#}$ & $348.5 \pm 4.5^{\#}$ & $358.5 \pm 16.3^{\#}$ \\
\hline
\end{tabular}

Data are means \pm SEM. ${ }^{*} P<0.05$ vs. NS group. ${ }^{\#} P<0.05$ vs. HS group.

We also examined the renalase protein expression levels and locations in the rat renal cortices by immunohis tochemistry analysis. Renalase was strongly expressed in the renal tubules and scattered in the glomeruli of the NS group (Fig. 4). In the HS renal tissue, the intensity and number of renalasepositive cells decreased. Quantification of renalasepositive areas in the kidneys, as summarized in Fig. 4A, indicated a significantly lower expression of renalase in the HS group than in the NS group $(P<0.01)$. In addition,

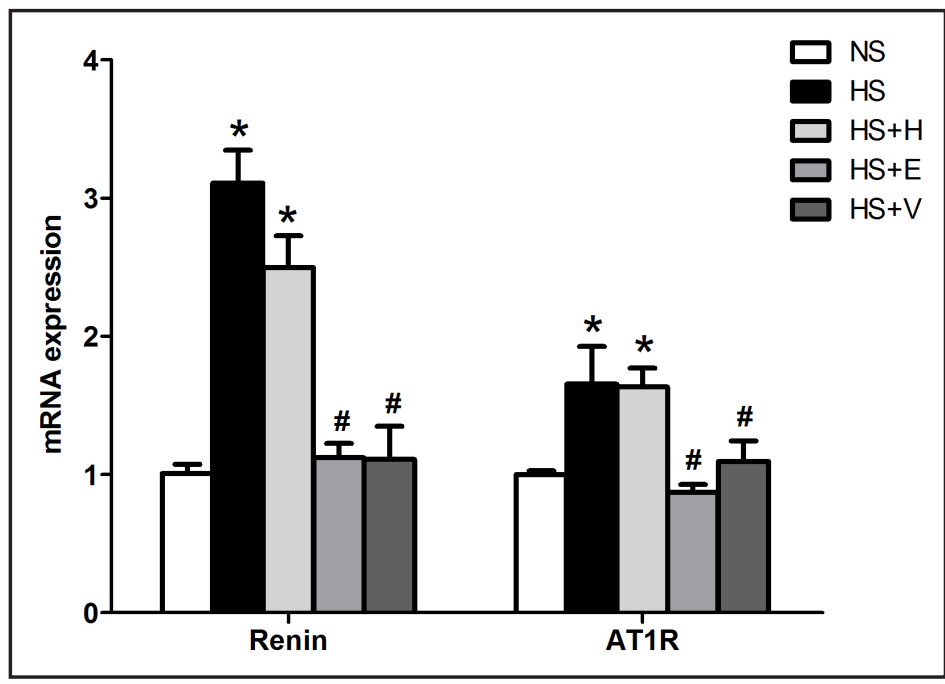

Fig. 2. The renin and AT1R mRNA expressions in renal cortex were quantified by real-time PCR and adjusted by GAPDH mRNA. ${ }^{*} \mathrm{P}<0.05$ vs. NS group. \# $\mathrm{P}<0.05$ vs. HS group. renalase expression was not increased by enalapril and valsartan in the treatment groups (Fig. 4).

\section{Discussion}

The results of the present study demonstrated that increased dietary sodium intake downregulates renal tissues and plasma renalase levels and significantly increases the expression of the key elements of the local RAS (renin and AT1R) in the kidney. Furthermore, the study showed that RAS inhibitors (enalapril and valsartan) could not alter the renal expression of renalase in SD rats given high-salt diet.

To date, a limited number of studies have shown the association between decreased renalase production and high sodium intake. Ghosh et al. [22] discovered that in Dahl saltsensitive rats fed with an $8 \%$ sodium chloride diet for three weeks, blood and kidney tissue renalase levels were significantly decreased. Quelhas-Santos et al. [23] reported that high salt intake markedly accentuated the decrease in blood and renal tissue renalase levels in rats that underwent 3/4 nephrectomy. More recently, in our study of dietary intervention, we found that low salt intake significantly increased serum renalase levels from the baseline, and high salt intake decreased serum renalase levels from those of low salt intake [16]. We further showed that dietary salt intake dramatically increases urinary renalase excretions 


\section{Kidney Blood Pressure Research}

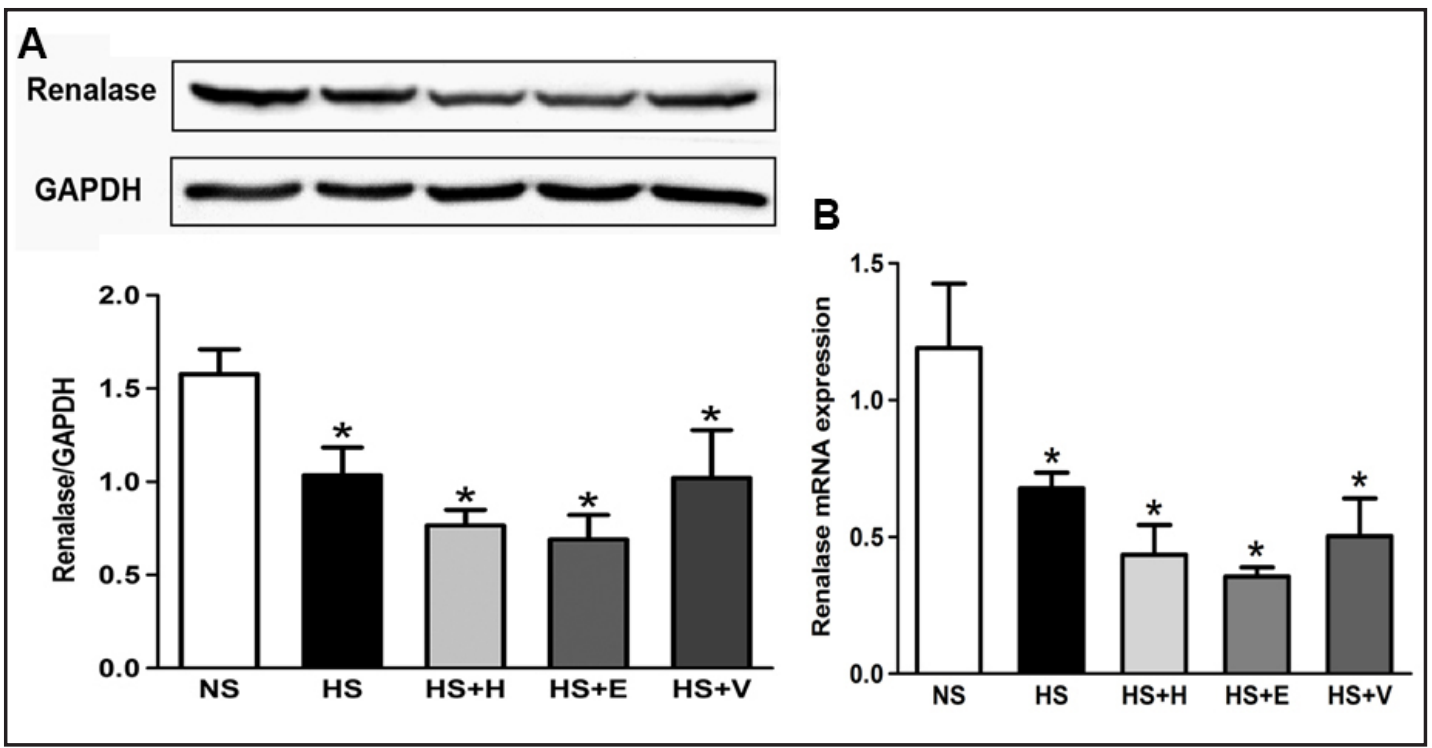

Fig. 3. The renalase protein (A) and mRNA (B) expression in renal cortex were measured by western blot and real-time PCR. ${ }^{*} \mathrm{P}<0.05$ vs. NS group.

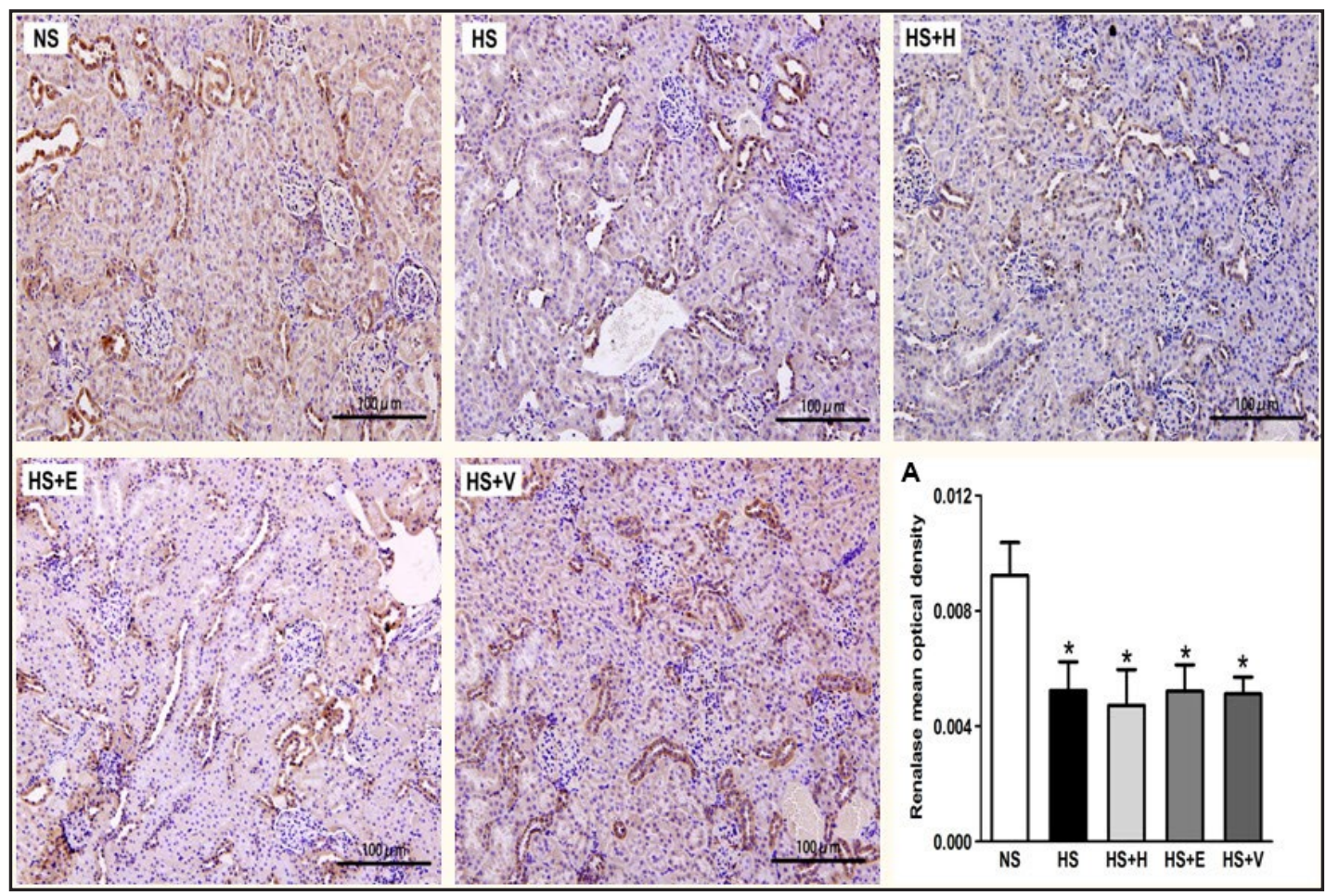

Fig. 4. Representative photomicrographs of renalase expression in kidneys visualized by immunochemistry staining in cortical areas (x200). (A) Bar graph showing quantitative analysis of renalase. ${ }^{*} P<0.05$ vs. NS group.

in the Chinese cohort [17]. This observation was unexpected mainly because high levels of dietary salt are believed to potentially reduce blood and kidney renalase levels. However, the changes in urinary renalase levels appear to be unaccounted by the changes in either 


\section{Kidney Blood Pressure Research}

Kidney Blood Press Res 2015;40:605-613

\begin{tabular}{|l|l|l|l|l}
\hline DOI: 10.1159/000368536 & (C) 2015 The Author(s). Published by S. Karger AG, Basel
\end{tabular}

Published on Ine: November 29, 2015 www.karger.com/kb

renal-tissue or circulating renalase levels. Furthermore, the source of urine renalase is not fully documented. Our family-based association study identified several single-nucleotide polymorphisms of the renalase gene, namely, rs919115, rs792205, and rs12356177, which were associated with BP responses to changes in dietary salt intake [18]. In a study by Fedchenko et al. [24] that involved SHR, the kidney renalase mRNA in rats with a moderate increase in BP (140 $\mathrm{mm} \mathrm{Hg}$ ) did not change as much as that in the control rats. In the current study, we observed pronounced decreases in renal and circulating renalase levels in the HS and $\mathrm{HS}+\mathrm{H}$ groups, which indicated that high salt intake, independent of BP, decreased the renalase expression in the SD rats. Although the mechanism by which excessive salt inhibits renalase is unknown, recent observations point to an important role for RAS.

In traditional theory, the normal response to increased salt intake is the suppression of the circulating RAS. However, recent studies suggest that renal RAS action varies independently or conversely with the plasma RAS in high salt intake, and the inappropriate activation of the intrarenal RAS may contribute directly to hypertension and renal damage. In Dahl salt-sensitive (DS) rats, Kobori et al. [25] showed that plasma renin activity and angiotensinogen (AGT) levels decreased but intrarenal AGT increased after high salt intake. This observation was also confirmed by Chandramohan et al., who suggested that high-salt diet lowers plasma renin activity but increases the number of kidney angiotensin II (Ang II)-positive cells and Ang II type 1 receptor (AT1R) in DS rats [26]. In a recent study, Wu et al. [27] reported that hypertension induced by high salt levels and renal damage causes the upregulation of renal cortex renin, AGT, and Ang II; in addition, the blockage of AT1R decreased the proteinuria in Wistar rats. These observations are consistent with the results of our study, in which high salt intake increased the mRNA expression of RAS components in the renal cortex, and the blockage of the angiotensin converting enzyme (ACE) and AT1R decreased the proteinuria. Previous studies also demonstrated that elevated Ang II not only induces hypertension but also elicits inflammatory and immunological responses that contribute to interstitial fibrosis, glomerulosclerosis, albuminuria, and finally, renal failure [28]. In the current study, the intrarenal RAS was inappropriately enhanced by high salt intake in the SD rats and associated with increased urinary protein excretions.

Experimental data provided evidence that the intrarenal RAS may be closely associated with renal expression induced by high salt. Han et al. [19] were the first to demonstrate that the ACE inhibitor lisinopril markedly increased the expression of renalase in the kidney tissues of rats with adriamycin-induced nephropathy. More recently, Zhou et al. [20] discovered that valsartan, an AT1R antagonist, promoted the stabilization of atherosclerotic plaque by increasing serum renalase and renalase expression in the fibrous cap of the atherosclerotic plaques in $\mathrm{ApoE}^{-/-}$mice fed with high-fat diet. Therefore, a high-salt load may reduce the expression of renalase in kidney secondary to activation of the renal RAS. Our results showed that blocking the action of the intrarenal RAS with either valsartan or enalapril did not significantly change the renal expression of renalase in rats treated with a high-salt diet. This finding may suggest that the inappropriate activation of intrarenal RAS may not contribute directly to the decreased renalase expression in rats that received highsalt diet. Although the mechanism(s) by which increased salt downregulates the expression of renalase in the kidney remains to be determined, experimental evidence has pointed to the importance of the intrarenal sympathetic nervous system in this process. High salt intake stimulates the sympathetic nervous system and facilitates catecholamine secretion and expression in the kidney [29,30]. Therefore, sympathetic activation may decrease the renal renalase expression as reported by Jiang et al. [31] In their study of spontaneously hypertensive rats, renal denervation lowered BP and upregulated the plasma renalase concentration and expression level in the kidney. However, we cannot exclude the possibility that other factors may participate in this process, which entails further investigation. 


\section{Kidney Bloód Pressure Research}

\section{Conclusion}

The present study demonstrated that high salt intake markedly reduced renalase expression and upregulated the local RAS processes in SD rat kidneys. Our results also suggested that the blockage of ACE or AT1R has no significant impact on the renal renalase expression in SD rats with high-salt diet. These findings may contribute to a better understanding of the roles of salt and RAS inhibitors in BP regulation and may provide potential clinical and public health implications.

\section{Disclosure Statement}

The authors declare that there is no conflict of interest.

\section{Acknowledgments}

We would like to thank Zhao Qiang from our laboratory for her technical assistance. This study was funded by grant 2012CB517804 from the National Program on Key Basic Research Project of China (973 Program) and grant 81370357 and 81570381 from the Natural Science Foundation of China.

\section{References}

1 Xu J, Li G, Wang P, Velazquez H, Yao X, Li Y, Wu Y, Peixoto A, Crowley S, Desir GV: Renalase is a novel, soluble monoamine oxidase that regulates cardiac function and blood pressure. J Clin Invest 2005;115:1275-1280.

- Wang F, Xing T, Li J, Bai M, Hu R, Zhao Z, Tian S, Zhang Z, Wang N: Renalase's expression and distribution in renal tissue and cells. PLoS One 2012;7:e46442.

- Desir GV, Wang L, Peixoto AJ: Human renalase: a review of its biology, function, and implications for hypertension. J Am Soc Hypertens 2012;6:417-426.

4 Wu Y, Xu J, Velazquez H, Wang P, Li G, Liu D, Sampaio-Maia B, Quelhas-Santos J, Russell K, Russell R, Flavell RA, Pestana M, Giordano F, Desir GV: Renalase deficiency aggravates ischemic myocardial damage. Kidney Int 2011;79:853-860.

5 Pandini V, Ciriello F, Tedeschi G, Rossoni G, Zanetti G, Aliverti A: Synthesis of human renalase1 in Escherichia coli and its purification as a FAD-containing holoprotein. Protein Expr Purif 2010;72:244-253.

6 Beaupre BA, Hoag MR, Moran GR: Renalase Does Not Catalyze the Oxidation of Catecholamines. Arch Biochem Biophys 2015;579:62-66.

7 Moran GR: The Catalytic Function of Renalase: A Decade of Phantoms. Biochim Biophys Acta DOI: 10.1016/j.bbapap.2015.04.010.

8 Milani M, Ciriello F, Baroni S, Pandini V, Canevari G, Bolognesi M, Aliverti A: FAD-binding site and NADP reactivity in human renalase: a new enzyme involved in blood pressure regulation. J Mol Biol 2011;411:463-473.

-9 Li X, Jiang W, Li L, Huang R, Yang Q Yang Y, Hong Y, Tang X: Renalase gene polymorphism in patients with hypertension and concomitant coronary heart disease. Kidney Blood Press Res 2014;39:9-16.

10 Pawlik A, Serdynska M, Dabrowska-Zamojcin E, Dziedziejko V, Safranow K,Domanski L, Ciechanowski K: Renalase gene polymorphism in patients after renal allograft transplantation. Kidney Blood Press Res 2014;39:58-64.

11 Wang F, Huang B, Li J, Liu L, Wang N: Renalase might be associated with hypertension and insulin resistance in Type 2 diabetes. Ren Fail 2014;36:552-556.

12 Zhang R, Li X, Liu N, Guo X, Liu W, Ning C, Wang Z, Sun L, Fu S: An association study on renalase polymorphisms and ischemic stroke in a Chinese population. Neuromolecular Med 2013;15:396-404. 


\section{Kidney \\ Blood Pressure Research}

Wang/Xie/Gao/Yan/Zheng/Lv/Cao/Hu/Yuan/Mu: RAS Inhibitors, Renalase and Salt

13 Meneton P, Jeunemaitre X, de Wardener HE, MacGregor GA: Links between dietary salt intake, renal salt handling, blood pressure, and cardiovascular diseases. Physiol Rev 2005;85:679-715.

14 Weinberger MH: Pathogenesis of salt sensitivity of blood pressure. Curr Hypertens Rep 2006;8:166-170.

15 Desir G: Novel insights into the physiology of renalase and its role in hypertension and heart disease. Pediatr Nephrol 2012;27:719-725.

16 Wang Y, Liu FQ, Wang D, Mu JJ, Ren KY, Guo TS, Chu C, Wang L, Geng LK, Yuan ZY: Effect of salt intake and potassium supplementation on serum renalase levels in Chinese adults: a randomized trial. Medicine (Baltimore) 2014;93:e44.

17 Wang Y, Wang D, Chu C, Mu JJ, Wang M, Liu FQ, Xie BQ, Yang F, Dong ZZ, Yuan ZY: Effect of Salt Intake and Potassium Supplementation on Urinary Renalase and Serum Dopamine Levels in Chinese Adults. Cardiology 2015;130:242-248.

-18 Wang Y, Chu C, Ren J, Mu J, Wang D, Liu F, Ren K, Guo T, Yuan Z: Genetic Variants in Renalase and Blood Pressure Responses to Dietary Salt and Potassium Interventions: A Family-Based Association Study. Kidney Blood Press Res 2014;39:497-506.

19 Han P, Sun H, Xu Y, Zeng Y, Yi W, Wu J, Shao M, Li S, Yi T: Lisinopril protects against the adriamycin nephropathy and reverses the renalase reduction: potential role of renalase in adriamycin nephropathy. Kidney Blood Press Res 2013;37:295-304.

20 Zhou M, Ma C, Liu W, Liu H, Wang N, Kang Q, Li P: Valsartan Promoting Atherosclerotic Plaque Stabilization by Upregulating Renalase: A Potential-Related Gene of Atherosclerosis. J Cardiovasc Pharmacol Ther 2015;20:509-519.

21 Wang Y, Mu JJ, Liu FQ, Ren KY, Xiao HY, Yang Z, Yuan ZY: Salt-induced epithelial-to-mesenchymal transition in Dahl salt-sensitive rats is dependent on elevated blood pressure. Braz J Med Biol Res 2014;47:223-230.

22 Ghosh SS, Gehr T, Sica DA, Masilamani S, Fakhry I, Wang R, McGuire E, Ghosh S: Renalase regulates blood pressure in salt sensitive Dahl rats. J Am Soc Nephrol 2006;17:208A.

23 Quelhas-Santos J, Sampaio-Maia B, Simoes-Silva L, Serrao P, Fernandes-Cerqueira C, Soares-Silva I, Pestana M: Sodium-dependent modulation of systemic and urinary renalase expression and activity in the rat remnant kidney. J Hypertens 2013;31:543-552.

24 Fedchenko V, Globa A, Buneeva O, Medvedev A: Renalase mRNA levels in the brain, heart, and kidneys of spontaneously hypertensive rats with moderate and high hypertension. Med Sci Monit Basic Res 2013;19:267-270.

25 Kobori H, Nishiyama A, Abe Y, Navar LG: Enhancement of intrarenal angiotensinogen in Dahl salt-sensitive rats on high salt diet. Hypertension 2003;41:592-597.

26 Chandramohan G, Bai Y, Norris K, Rodriguez-Iturbe B, Vaziri ND: Effects of dietary salt on intrarenal angiotensin system, NAD(P)H oxidase, COX-2, MCP-1 and PAI-1 expressions and NF-kappaB activity in saltsensitive and -resistant rat kidneys. Am J Nephrol 2008;28:158-167.

-27 Wu H, Liang Y, Zheng Y, Bai Q, Zhuang Z, A L, Zheng D, Wang Y: Up-regulation of intrarenal renin-agiotensin system contributes to renal damage in high-salt induced hypertension rats. Kidney Blood Press Res 2014;39:526-535.

28 Muller DN, Shagdarsuren E, Park JK, Dechend R, Mervaala E, Hampich F, Fiebeler A, Ju X, Finckenberg P, Theuer J, Viedt C, Kreuzer J, Heidecke H, Haller H, Zenke M, Luft FC: Immunosuppressive treatment protects against angiotensin II-induced renal damage. Am J Pathol 2002;161:1679-1693.

-29 Stocker SD, Madden CJ, Sved AF: Excess dietary salt intake alters the excitability of central sympathetic networks. Physiol Behav 2010;100:519-524.

-30 Dietz R, Schomig A, Rascher W, Strasser R, Kubler W: Enhanced sympathetic activity caused by salt loading in spontaneously hypertensive rats. Clin Sci (Lond) 1980;59:171s-173s.

31 Jiang W, Guo Y, Tan L, Tang X, Yang Q Yang K: Impact of renal denervation on renalase expression in adult rats with spontaneous hypertension. Exp Ther Med 2012;4:493-496. 